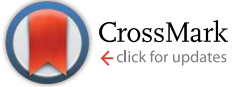

Cite this: Chem. Sci., 2016, 7, 1867

Received 27th October 2015 Accepted 25th November 2015

DOI: $10.1039 / \mathrm{c5sc04069h}$

www.rsc.org/chemicalscience

\section{Decoration of $\mathrm{Pt}$ on $\mathrm{Cu} / \mathrm{Co}$ double-doped $\mathrm{CeO}_{2}$ nanospheres and their greatly enhanced catalytic activity $\dagger$}

\begin{abstract}
Fan Wang, ${ }^{\mathrm{b}}$ Wang $\mathrm{Li}^{\mathrm{a}}{ }$ Xilan Feng, ${ }^{\mathrm{a}}$ Dapeng Liu${ }^{\star a}$ and Yu Zhang ${ }^{\star a}$
In this paper, we report an efficient strategy for the synthesis of $\mathrm{Cu} / \mathrm{Co}$ double-doped $\mathrm{CeO}_{2}$ nanospheres $\left(\mathrm{Cu}_{x} \mathrm{CO}_{1-x}-\mathrm{CeO}_{2}-\mathrm{Pt}, \mathrm{O} \leq x \leq 1\right)$, which were fabricated via a simple water-glycol system. The following in situ surface decoration of Pt nanoparticles make these nanospheres highly active for the catalytic reduction of nitrophenol and $\mathrm{CO}$ oxidation. Detailed tests show that their catalytic performance strongly depends on the doping components and ion concentration of $\mathrm{Cu}$ and $\mathrm{Co}$ ions. The best samples of $\mathrm{Cu}_{0.50} \mathrm{CO}_{0.50^{-}}$ $\mathrm{CeO}_{2}-\mathrm{Pt}$ and $\mathrm{Cu}_{0.34} \mathrm{CO}_{0.66}-\mathrm{CeO}_{2}-\mathrm{Pt}$ demonstrate an excellent turnover frequency (TOF) of more than $450 \mathrm{~h}^{-1}$ after five cycles and retains about $99 \%$ conversion by using $\mathrm{NH}_{3} \mathrm{BH}_{3}$ as a reductant to reduce nitrophenol. Moreover, $\mathrm{Cu}_{0.50} \mathrm{CO}_{0.50}-\mathrm{CeO}_{2}-\mathrm{Pt}$ possesses a much lower light-off and $T_{100}$ (the temperature for $100 \%$ CO oxidation) temperature compared with the other catalysts.
\end{abstract}

\section{Introductions}

Among the metal oxides, $\mathrm{CeO}_{2}$ has attracted great attention due to its excellent physicochemical properties including its good optical properties, mechanical strength, oxygen ion conductivity, and high thermal stability. $\mathrm{CeO}_{2}$ has a fluorite-like cubic structure with each $\mathrm{Ce}^{4+}$ ion surrounded by eight $\mathrm{O}^{2-}$ ions in a face-centered cubic (fcc) arrangement, whereas each $\mathrm{O}^{2-}$ ion is tetrahedrally surrounded by four $\mathrm{Ce}^{4+}$ ions. Intrinsic oxygen vacancy defects can be rapidly formed and eliminated in the lattice of $\mathrm{CeO}_{2}$, which favors mediation of lattice expansion and strain, and hence contributes significantly towards stable grain boundary structures. Hence, $\mathrm{CeO}_{2}$ has been successfully employed in various applications such as in energy and magnetic data storage, ${ }^{1}$ photocatalytic applications, ${ }^{2-4}$ as sensors for $\mathrm{CO},{ }^{5-9} \mathrm{H}_{2} \mathrm{O}_{2},{ }^{10} \mathrm{NH}_{3},{ }^{11}$ and nitrophenol, ${ }^{12,13}$ as a UV blocker, ${ }^{14}$ in solar fuel synthesis, ${ }^{15}$ water oxidation, ${ }^{16,17}$ oxygen transfer, ${ }^{18}$ fuel cells, ${ }^{19,20}$ gates for metal-oxide semiconductor devices ${ }^{21}$ as a promoter in three-way catalysts for the elimination of polluted auto-exhaust gases from vehicles, ${ }^{22-24}$ and so on.

The larger the amount of oxygen vacancies that $\mathrm{CeO}_{2}$ possesses, the more efficient it will be for storing oxygen. Thus, it seems meaningful to control the generation of oxygen vacancies to improve its physicochemical properties.

${ }^{a}$ Key Laboratory of Bio-Inspired Smart Interfacial Science and Technology of Ministry of Education, School of Chemistry and Environment, Beihang University, Beijing 100191, P.R. China.E-mail: liudp@buaa.edu.cn; jade@buaa.edu.cn

${ }^{b}$ State Key Laboratory of Rare Earth Resource Utilization, Changchun Institute of Applied Chemistry, Chinese Academy of Science, Changchun, 130022 Jilin, China

$\dagger$ Electronic supplementary information (ESI) available. See DOI: $10.1039 / \mathrm{c} 5 \mathrm{sc} 04069 \mathrm{~h}$
Endeavours have been devoted to introduce dopants to improve the catalytic performance of $\mathrm{CeO}_{2}$. It has been reported that its catalytic activity can be considerably enhanced by tuning the surface and interface structure through doping with isovalent/ aliovalent cations into the $\mathrm{CeO}_{2}$ lattice. ${ }^{25-30}$ The isovalent cations that are frequently used are $\mathrm{Ti}^{4+}, \mathrm{Zr}^{4+}, \mathrm{Hf}^{4+}$, and $\mathrm{Sn}^{4+}$, while aliovalent cations used include $\mathrm{Mn}^{2+}, \mathrm{Ni}^{2+}, \mathrm{Zn}^{2+}, \mathrm{Ca}^{2+}$, $\mathrm{Mn}^{3+}, \mathrm{Sc}^{3+}, \mathrm{Y}^{3+}, \mathrm{Gd}^{3+}, \mathrm{Sm}^{3+}, \mathrm{Eu}^{3+}, \mathrm{La}^{3+}$, etc. The substitution of isovalent dopants into the $\mathrm{CeO}_{2}$ lattice decreases the oxygen vacancy formation energy due to structural distortion, whereas in the case of aliovalent dopants, the decrease in the defect formation energy is due to structural distortion as well as electronic modification, resulting in the generation of extra oxygen vacancies. ${ }^{31,32}$ So once noble metals or metal oxides form hybrids with $\mathrm{CeO}_{2}$, they often exhibit greatly enhanced catalytic activity, stability and selectivity.

Noble metal nanoparticles have been extensively studied for decades due to their high performance in many kinds of catalytic reactions. Smaller sized noble metal nanoparticles often have a larger fraction of exposed atoms on the particle surface, demonstrating better catalytic activity. Moreover, the strong synergistic effect between noble metals and the support greatly favors improvement of the catalytic performance, ${ }^{33-38}$ especially for Pt- $\mathrm{CeO}_{2}$ systems. ${ }^{39-44}$ A recent report by Chowdhury et al., reveals that doping can influence the surface acid-base properties of mesoporous $\mathrm{CeO}_{2}$ and its catalytic behavior. ${ }^{43}$ It is highly expected that incorporation of the cations into a ceria lattice structure will influence the redox properties of ceria in favour of synergistic interactions with noble metal nanoparticles towards enhanced activity for catalytic nitrophenol reduction and $\mathrm{CO}$ oxidation. 
In this paper, an efficient strategy was developed for the synthesis of $\mathrm{Cu}_{x} \mathrm{Co}_{1-x}-\mathrm{CeO}_{2}-\mathrm{Pt}$ hybrids. First, double-doped $\mathrm{CeO}_{2}$ nanospheres were fabricated in a water-glycol mixed system, followed by a self-assembly process to in situ deposit Pt nanoparticles on the surface of the as-obtained double-doped $\mathrm{CeO}_{2}$ nanospheres to form the final hybrids. Then, the as-obtained catalysts with different doping components were studied in detail to find the optimal doping ratios with the best catalytic performance for the reduction of 4-NP (4-nitrophenol) by $\mathrm{NH}_{3} \mathrm{BH}_{3}$ and the oxidation of CO. Furthermore, a detailed discussion has been made to clarify the role of the doping elements in the reduction of 4-NP and oxidation of CO, according to the analytical results.

\section{Experimental section}

\section{Synthesis of $\mathrm{CeO}_{2}$ nanospheres:}

The synthesis of $\mathrm{CeO}_{2}$ nanospheres was carried out by a previously reported method. ${ }^{45} 500 \mathrm{mg}$ of $\mathrm{Ce}\left(\mathrm{NO}_{3}\right)_{3} \cdot 6 \mathrm{H}_{2} \mathrm{O}$ and $200 \mathrm{mg}$ of PVP were dissolved in $14 \mathrm{~mL}$ of ethylene glycol, and then 1 $\mathrm{mL}$ of deionized water was added to the above solution. After continuous stirring for $30 \mathrm{~min}$, the clear solution was transferred into a Teflon-lined autoclave of $20 \mathrm{~mL}$ capacity and heated for $8 \mathrm{~h}$ at $160{ }^{\circ} \mathrm{C}$. When the autoclave was cooled at room temperature, the products were collected and washed with deionized water and absolute alcohol several times. Finally, the products were dried at $60{ }^{\circ} \mathrm{C}$ overnight, and then calcined at 300 ${ }^{\circ} \mathrm{C}$ for $1 \mathrm{~h}$ at $1{ }^{\circ} \mathrm{C} \min ^{-1}$.

\section{Synthesis of $\mathrm{Cu}_{x} \mathrm{Co}_{1-x}-\mathrm{CeO}_{2}$ nanospheres}

$500 \mathrm{mg}$ of $\mathrm{Ce}\left(\mathrm{NO}_{3}\right)_{3} \cdot 6 \mathrm{H}_{2} \mathrm{O}$ and $200 \mathrm{mg}$ of PVP were dissolved in $14 \mathrm{~mL}$ of ethylene glycol, and then $0.66 \mathrm{~mL}$ of $20 \mathrm{mg} \mathrm{mL}$ $\mathrm{CuCl}_{2} \cdot 2 \mathrm{H}_{2} \mathrm{O}$ and $0.34 \mathrm{~mL}$ of a $20 \mathrm{mg} \mathrm{mL}{ }^{-1} \mathrm{CoCl}_{2} \cdot 2 \mathrm{H}_{2} \mathrm{O}$ solution were added to the above solution. The mixed solutions were transferred into a Teflon-lined autoclave of $20 \mathrm{~mL}$ capacity and heated for $8 \mathrm{~h}$ at $160{ }^{\circ} \mathrm{C}$. When the autoclave was cooled to room temperature, the products were collected and washed with deionized water and absolute alcohol several times. Finally, the products were dried at $60^{\circ} \mathrm{C}$ overnight, and then calcined at 300 ${ }^{\circ} \mathrm{C}$ at $1{ }^{\circ} \mathrm{C} \min ^{-1}$ for $1 \mathrm{~h}$. The above products were labeled as $\mathrm{Cu}_{0.66} \mathrm{Co}_{0.34}-\mathrm{CeO}_{2}$. $\mathrm{Cu}-\mathrm{CeO}_{2}, \mathrm{Cu}_{0.50} \mathrm{Co}_{0.50}-\mathrm{CeO}_{2}, \mathrm{Cu}_{0.34} \mathrm{Co}_{0.66^{-}}$ $\mathrm{CeO}_{2}$ and $\mathrm{Co}-\mathrm{CeO}_{2}$ were prepared in a similar process, except for changing the $\mathrm{CuCl}_{2} \cdot 2 \mathrm{H}_{2} \mathrm{O} / \mathrm{CoCl}_{2} \cdot 2 \mathrm{H}_{2} \mathrm{O}(\mathrm{v} / \mathrm{v})$ to $1 \mathrm{~mL}$ $\mathrm{CuCl}_{2} \cdot 2 \mathrm{H}_{2} \mathrm{O}$ and $0 \mathrm{~mL} \mathrm{CoCl} \cdot 2 \mathrm{H}_{2} \mathrm{O}, 0.5 \mathrm{~mL} \mathrm{CuCl}_{2} \cdot 2 \mathrm{H}_{2} \mathrm{O}$ and 0.5 $\mathrm{mL} \mathrm{CoCl}_{2} \cdot 2 \mathrm{H}_{2} \mathrm{O}, 0.34 \mathrm{~mL} \mathrm{CuCl}_{2} \cdot 2 \mathrm{H}_{2} \mathrm{O}$ and $0.66 \mathrm{~mL} \mathrm{CoCl}_{2}-$ $\cdot 2 \mathrm{H}_{2} \mathrm{O}$, and $0 \mathrm{~mL} \mathrm{CuCl}_{2} \cdot 2 \mathrm{H}_{2} \mathrm{O}$ and $1 \mathrm{~mL} \mathrm{CoCl}_{2} \cdot 2 \mathrm{H}_{2} \mathrm{O}$, respectively.

\section{Synthesis of $\mathrm{Cu}_{x} \mathrm{Co}_{1-x}-\mathrm{CeO}_{2}-\mathrm{Pt}$ hybrids}

$70 \mathrm{mg}$ of $\mathrm{Cu}_{x} \mathrm{Co}_{1-x}-\mathrm{CeO}_{2}$ nanospheres and $42 \mathrm{mg}$ of PVP were first dissolved in $60 \mathrm{~mL}$ of ethylene glycol. After that, $0.84 \mathrm{~mL}$ of $0.02 \mathrm{M} \mathrm{K}_{2} \mathrm{PtCl}_{4}$ aqueous solution was added to the above solution. Then, the mixture was heated to $110{ }^{\circ} \mathrm{C}$ and was maintained at this temperature for $2 \mathrm{~h}$. The product was collected by centrifugation and washed with deionized water several times and dried in an oven.

\section{Characterization}

The X-ray diffraction patterns of the products were collected on a Rigaku-D/max $2500 \mathrm{~V}$ X-ray diffractometer with $\mathrm{Cu}_{\mathrm{K} \alpha}$ radiation $(\lambda=1.5418 \AA)$, with an operation voltage and current maintained at $40 \mathrm{kV}$ and $40 \mathrm{~mA}$. Transmission electron microscopic (TEM) images were obtained with a TECNAI G2 high-resolution transmission electron microscope operating at $200 \mathrm{kV}$. Inductively coupled plasma (ICP) analyses were performed with a Varian Liberty 200 spectrophotometer to determine the contents. X-ray photoelectron spectroscopy (XPS) measurements were taken on an ESCALAB-MKII 250 photoelectron spectrometer (VG Co.) with $\mathrm{Al}_{\mathrm{K} \alpha} \mathrm{X}$-ray radiation as the X-ray source for excitation. Decreases in the concentration of 4-NP were analyzed by UV-vis-NIR (SHIMADZU, UV-3600) spectrophotometer. The catalytic performances of the catalysts for $\mathrm{CO}$ oxidation were monitored on-line by gas chromatography (GC9800).

\section{Catalytic tests}

Chemical reduction of nitrophenol by $\mathrm{NH}_{3} \mathrm{BH}_{3}$ : aqueous solutions of 4 -NP $(0.01 \mathrm{M})$ and $\mathrm{NH}_{3} \mathrm{BH}_{3}(0.1 \mathrm{M})$ were freshly prepared. $20 \mu \mathrm{L}$ of the 4-NP solution and $100 \mu \mathrm{L}$ of the $\mathrm{NH}_{3} \mathrm{BH}_{3}$ solution were added to a quartz cuvette containing $2 \mathrm{~mL}$ of water. Then, $20 \mu \mathrm{L}$ of $5 \mathrm{mg} \mathrm{mL} \mathrm{m}^{-1}$ catalysts were injected into the cuvette to start the reaction. Since the spectrophotometer has a function to display the instant absorbance of a fixed absorption peak such as $400 \mathrm{~nm}$, we can easily monitor the intensity of the absorption peak at $400 \mathrm{~nm}$ as a function of time. After each round of reaction, another $20 \mu \mathrm{L}$ of 4 -NP solution and $100 \mu \mathrm{L}$ $\mathrm{NH}_{3} \mathrm{BH}_{3}$ aqueous solution were added to the reaction solution. This step was repeated 10 times to study the stability of the catalysts. The reduction of 4 - $\mathrm{NP}$ by $\mathrm{NH}_{3} \mathrm{BH}_{3}$ can be briefly expressed as follows:

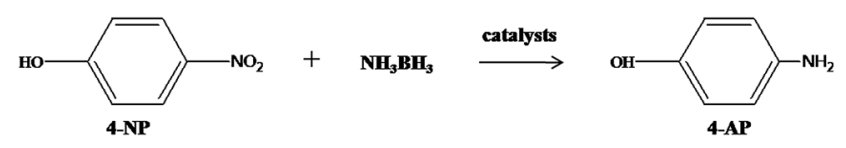

\section{CO oxidation}

$20 \mathrm{mg}$ of catalysts were put in a stainless steel reaction tube. The CO oxidation tests were performed under conditions in 1\% CO and $20 \% \mathrm{O}_{2}$ in $\mathrm{N}_{2}$ at a total flow rate of $30 \mathrm{~mL} \mathrm{~min} \mathrm{~m}^{-1}$, and a space velocity (SV) of $90000 \mathrm{~mL} \mathrm{~h}^{-1} \mathrm{~g}_{\text {cat }}{ }^{-1}$. The composition of the gas was monitored on-line by gas chromatography.

\section{Results and discussion}

The synthesis of the $\mathrm{Cu}_{x} \mathrm{Co}_{1-x}-\mathrm{CeO}_{2}-\mathrm{Pt}$ hybrid nanocatalysts involved two steps. Uniform $\mathrm{Cu}_{x} \mathrm{Co}_{1-x}-\mathrm{CeO}_{2}$ nanospheres were first acquired by tuning the doping concentration of $\mathrm{Co}^{2+}$ and $\mathrm{Cu}^{2+}$, and then they served as a support for the in situ deposition of Pt nanoparticles on their surface. Fig. 1 shows typical SEM images of the as-obtained $\mathrm{Cu}_{x} \mathrm{Co}_{1-x}-\mathrm{CeO}_{2}$ samples, in which some detailed morphological and structural features can be found. All these samples are sphere-like with no obvious 

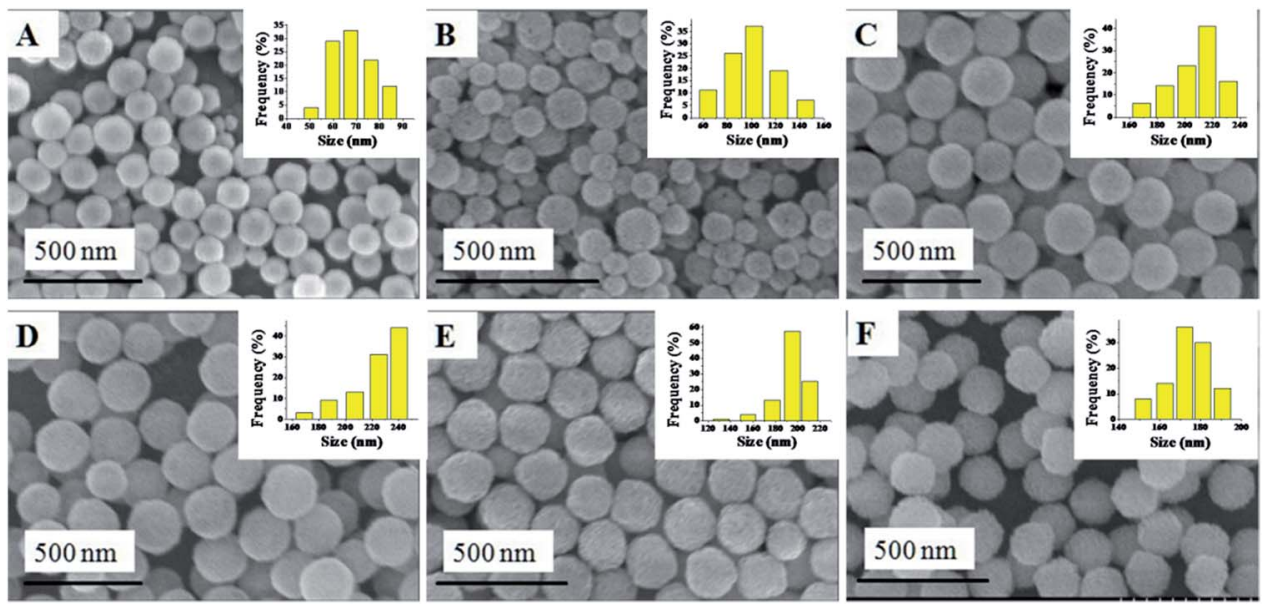

Fig. 1 SEM images of (A) $\mathrm{Cu}-\mathrm{CeO}_{2} ;(\mathrm{B}) \mathrm{Cu}_{0.66} \mathrm{Co}_{0.34}-\mathrm{CeO}_{2} ;$ (C) $\mathrm{Cu}_{0.50} \mathrm{Co}_{0.50}-\mathrm{CeO}_{2} ;$ (D) $\mathrm{Cu}_{0.34} \mathrm{Co}_{0.66}-\mathrm{CeO}_{2} ;(\mathrm{E}) \mathrm{Co}_{-}-\mathrm{CeO}_{2} ;$ (F) $\mathrm{CeO}$.

fragments. Their size distributions are shown in Fig. 1 (inset) and are listed in Table S1. $\dagger$ Compared with the pure $\mathrm{CeO}_{2}$ nanospheres of $174 \mathrm{~nm}$, the $\mathrm{Cu}$-rich ones are much smaller and are even less than $100 \mathrm{~nm}$, while those Co-rich samples show a bigger size around $200 \mathrm{~nm}$. Fig. 2 shows the SEM images of the as-obtained samples after the addition of $\mathrm{K}_{2} \mathrm{PtCl}_{4}$ aqueous solution and after being refluxed at $110^{\circ} \mathrm{C}$ for $2 \mathrm{~h}$. However, it is hard for us to distinguish the differences of the surface from the $\mathrm{Cu}_{x} \mathrm{Co}_{1-x}-\mathrm{CeO}_{2}$ nanospheres, and no Pt particles can be found, indicating that the size of the deposited Pt nanoparticles should be very small in the $\mathrm{Cu}_{x} \mathrm{Co}_{1-x}-\mathrm{CeO}_{2}-\mathrm{Pt}$ hybrids. The sizes of the as-obtained $\mathrm{Cu}_{x} \mathrm{Co}_{1-x}-\mathrm{CeO}_{2}-\mathrm{Pt}$ hybrids are shown in Table S2. $\dagger$

TEM characterization can tell us more information about the final $\mathrm{Cu}_{x} \mathrm{Co}_{1-x}-\mathrm{CeO}_{2}-\mathrm{Pt}$ hybrids. As shown in Fig. 3, these $\mathrm{Cu}_{x} \mathrm{Co}_{1-x}-\mathrm{CeO}_{2}-\mathrm{Pt}$ hybrids maintained their initial morphologies and inner nanostructures well. With a decrease in the amount of $\mathrm{Cu}^{2+}$ doping, the double-doped $\mathrm{CeO}_{2}$ nanospheres obviously underwent a morphology transformation from hollow to core-shell, and then to be solid. The high-resolution TEM image in Fig. 3 shows that each $\mathrm{Cu}_{x} \mathrm{Co}_{1-x}-\mathrm{CeO}_{2}-\mathrm{Pt}$ nanosphere is decorated by hundreds of ultra-small Pt nanoparticles (less than $2 \mathrm{~nm}$ ) and the $\mathrm{Cu}_{x} \mathrm{Co}_{1-x}-\mathrm{CeO}_{2}$ nanospheres are composed of closely packed $\mathrm{CeO}_{2}$ nanoparticles with diameters of about 5 $\mathrm{nm}$ as primary building blocks. The clearly observed lattice spacing listed in Table $\mathrm{S} 3 \dagger$ agrees well with that of Pt (200) $(0.196 \mathrm{~nm})$ and $\mathrm{CeO}_{2}(111)(0.312 \mathrm{~nm})$. The high angle annular dark field scanning transmission electron microscopy (HAADFSTEM) images of $\mathrm{Cu}_{0.66} \mathrm{Co}_{0.34}-\mathrm{CeO}_{2}-\mathrm{Pt}$ demonstrate the evenly distributed $\mathrm{Cu}, \mathrm{Pt}$ and Co elements, as shown in Fig. 4.

In the X-ray diffraction (XRD) patterns of the $\mathrm{Cu}_{x} \mathrm{Co}_{1-x^{-}}$ $\mathrm{CeO}_{2}-\mathrm{Pt}$ and $\mathrm{CeO}_{2}-\mathrm{Pt}$ nanospheres (Fig. 5), the diffraction peaks of all the products can be indexed to a pure phase of fcc $\mathrm{CeO}_{2}$ structures (JCPDS no. 34-0394). The peaks at $2 \theta=28.549^{\circ}$, $33.077^{\circ}, 47.483^{\circ}, 56.342^{\circ}, 59.09^{\circ}, 69.416^{\circ}, 76.704^{\circ}$ and $79.077^{\circ}$ correspond to the characteristic (111), (200), (220), (311), (222), (400), (331) and (420) reflections, respectively. No signals related to impurities, such as cobalt oxide or copper oxide, can be found for all samples, indicating the homogeneous doping of
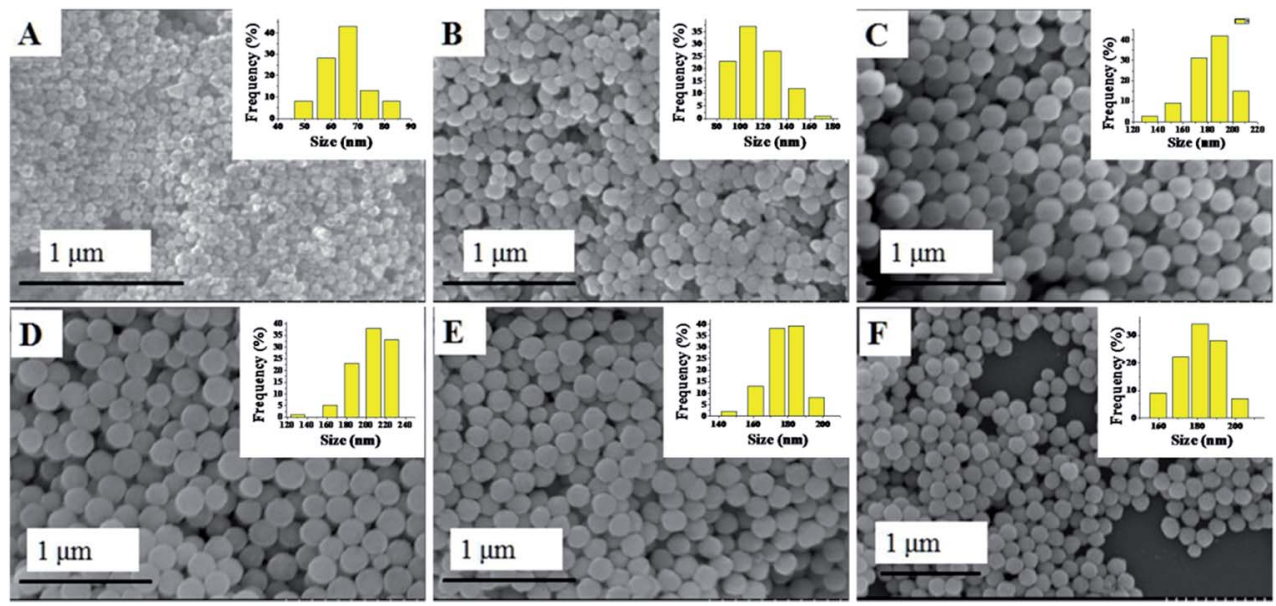

Fig. 2 SEM images of (A) $\mathrm{Cu}-\mathrm{CeO}_{2}-\mathrm{Pt}$; (B) $\mathrm{Cu}_{0.66} \mathrm{Co}_{0.34}-\mathrm{CeO}_{2}-\mathrm{Pt}$; (C) $\mathrm{Cu}_{0.50} \mathrm{Co}_{0.50}-\mathrm{CeO}_{2}-\mathrm{Pt}$; (D) $\mathrm{Cu}_{0.34} \mathrm{Co}_{0.66}-\mathrm{CeO}_{2}-\mathrm{Pt}$; (E) $\mathrm{Co}-\mathrm{CeO}_{2}-\mathrm{Pt}$; (F) $\mathrm{CeO}_{2}-\mathrm{Pt}$. 

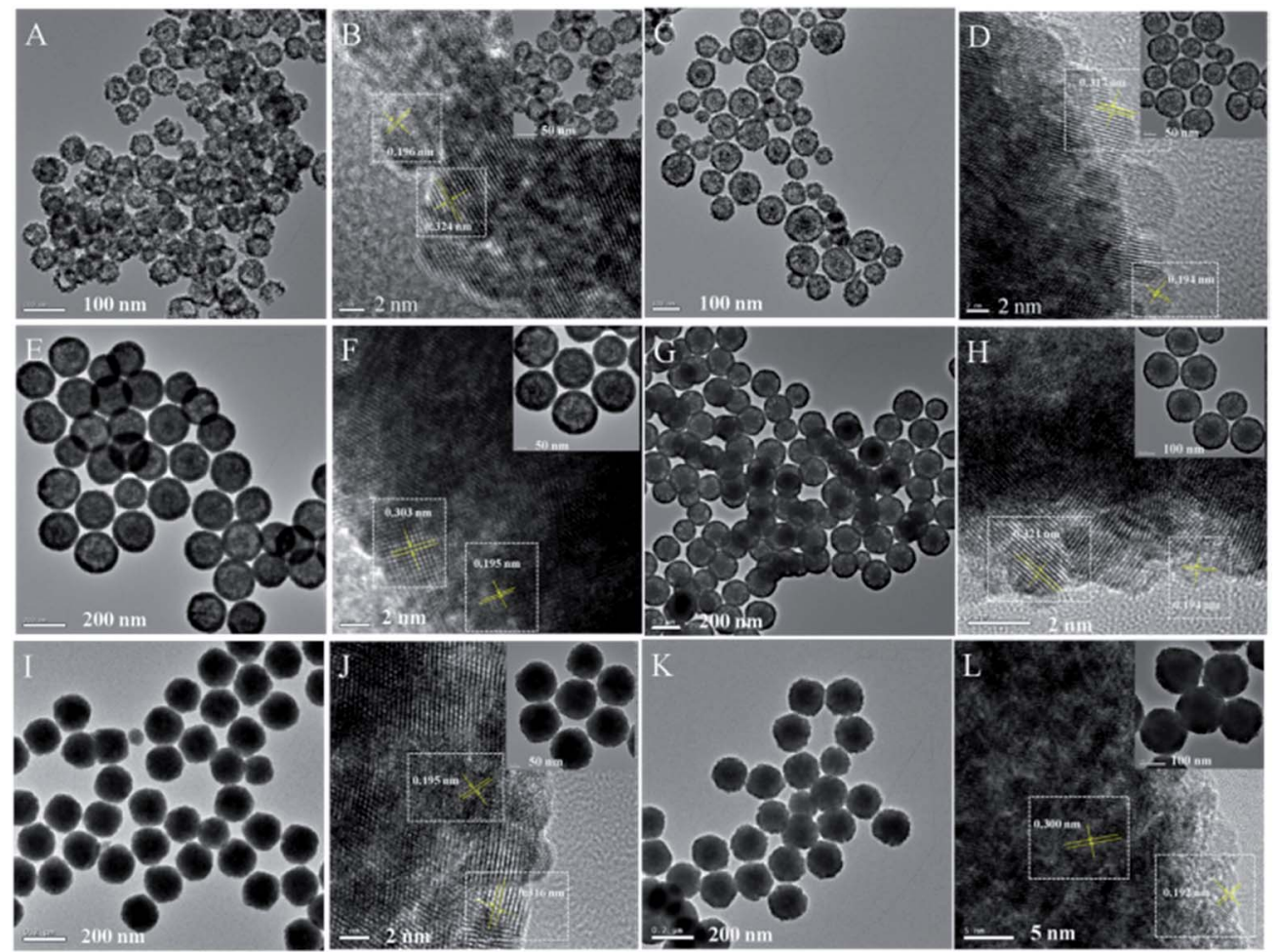

Fig. 3 TEM images of (A) and (B) $\mathrm{Cu}-\mathrm{CeO}_{2}-\mathrm{Pt}$; (C) and (D) $\mathrm{Cu}_{0.66} \mathrm{Co}_{0.34}-\mathrm{CeO}_{2}-\mathrm{Pt}$; (E) and (F) $\mathrm{Cu}_{0.50} \mathrm{Co}_{0.50}-\mathrm{CeO}_{2}-\mathrm{Pt}$; (G) and (H) $\mathrm{Cu}_{0.34} \mathrm{Co}_{0.66}-$ $\mathrm{CeO}_{2}-\mathrm{Pt}$; (I) and (J) $\mathrm{Co}-\mathrm{CeO}_{2}-\mathrm{Pt}$; (K) and (L) $\mathrm{CeO}_{2}-\mathrm{Pt}$.
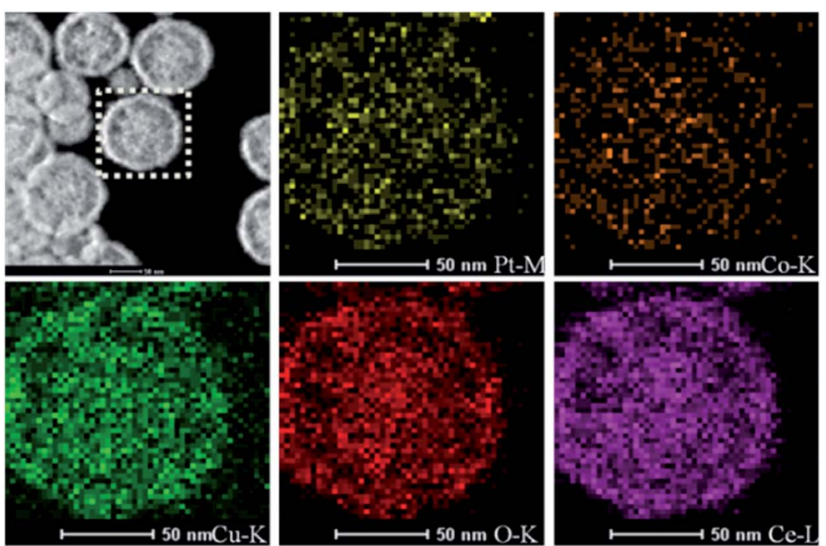

Fig. 4 HAADF-STEM images of $\mathrm{Cu}_{0.66} \mathrm{CO}_{0.34}-\mathrm{CeO}_{2}-\mathrm{Pt}$ nanospheres.

$\mathrm{Cu}$ and $\mathrm{Co}$ ions in the $\mathrm{CeO}_{2}$ solid solutions. The contents of the elements $\mathrm{Cu}$, $\mathrm{Co}$, Ce and $\mathrm{Pt}$ for the $\mathrm{Cu}_{x} \mathrm{Co}_{1-x}-\mathrm{CeO}_{2}-\mathrm{Pt}$ nanospheres were then determined by ICP-MS analysis and are listed in Table S4. $\dagger$ It can be seen that the loading amounts of Pt (mol\%) are less than $1.4 \%$ if $\mathrm{Cu}^{2+}$ is introduced, however, in the absence of $\mathrm{Cu}^{2+}$, this percentage increased to $4.1 \%$ for $\mathrm{Co}-$ $\mathrm{CeO}_{2}-\mathrm{Pt}$ and $4.8 \%$ for $\mathrm{CeO}_{2}-\mathrm{Pt}$, which were much higher than the others. On the contrary, $\mathrm{Co}^{2+}$ doping has little effect on the deposition amount of Pt.

XPS analysis was employed to determine the surface elements and their valence states of the $\mathrm{Cu}_{x} \mathrm{Co}_{1-x}-\mathrm{CeO}_{2}-\mathrm{Pt}$ and $\mathrm{CeO}_{2}-\mathrm{Pt}$ nanospheres (Fig. 6). All of the samples show

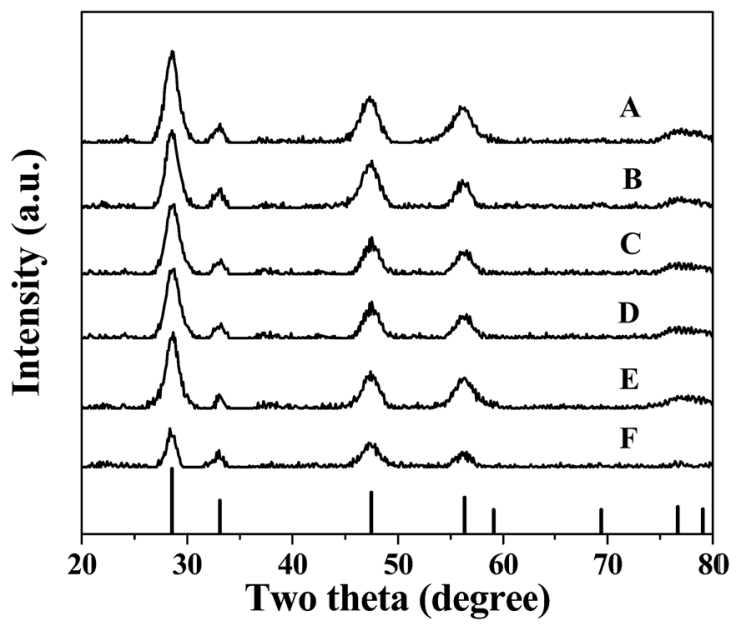

Fig. 5 XRD patterns of (A) $\mathrm{Cu}-\mathrm{CeO}_{2}-\mathrm{Pt}$; (B) $\mathrm{Cu}_{0.66} \mathrm{CO}_{0.34}-\mathrm{CeO}_{2}-\mathrm{Pt}$; (C) $\mathrm{Cu}_{0.50} \mathrm{Co}_{0.50}-\mathrm{CeO}_{2}-\mathrm{Pt}$; (D) $\mathrm{Cu}_{0.34} \mathrm{Co}_{0.66}-\mathrm{CeO}_{2}-\mathrm{Pt}$; (E) $\mathrm{Co}-$ $\mathrm{CeO}_{2}-\mathrm{Pt}$; (F) $\mathrm{CeO}_{2}-\mathrm{Pt}$.

characteristic peaks at the binding energies of $71.3 \mathrm{eV}\left(\mathrm{Pt} 4 \mathrm{f}_{7 / 2}\right)$ and $74.7 \mathrm{eV}\left(\mathrm{Pt} 4 \mathrm{f}_{5 / 2}\right)$ of the element Pt, and the two peaks at 882.8 and $899.5 \mathrm{eV}$ correspond well to the Ce $3 \mathrm{~d}_{5 / 2}$ and Ce $3 \mathrm{~d}_{3 / 2}$ spin-orbit peaks of $\mathrm{CeO}_{2}$. As previously reported, the XPS spectrum of Co 2p shows two major peaks at 795.5 and $780.4 \mathrm{eV}$, corresponding to Co $2 \mathrm{p}_{1 / 2}$ and Co $2 \mathrm{p}_{3 / 2}$ spin-orbit coupling, respectively. ${ }^{46}$ Two major peaks lying at 932.2 and $954.2 \mathrm{eV}$ are characteristic signals of $\mathrm{Cu}^{2+}$ with $\mathrm{Cu} 2 \mathrm{p}_{3 / 2}$ and $\mathrm{Cu} 2 \mathrm{p}_{1 / 2}$ orbits, 

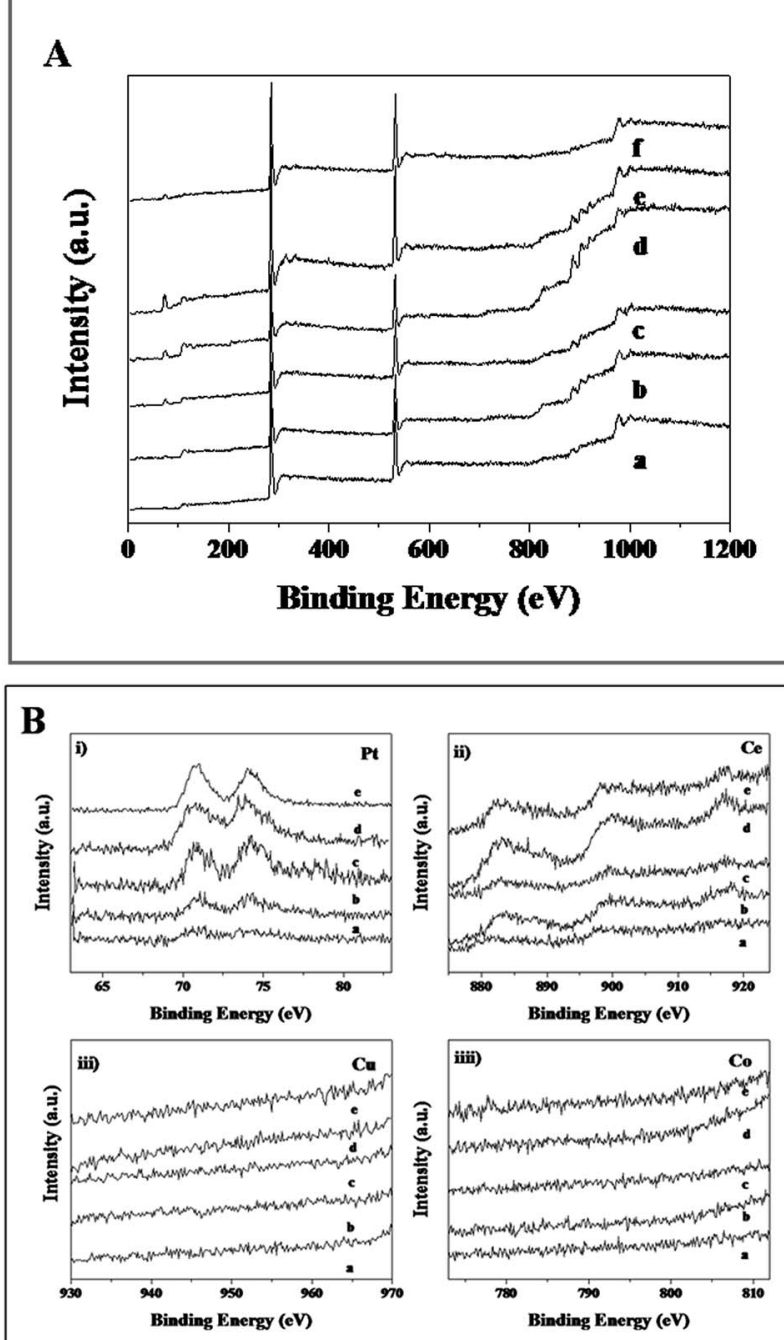

Fig. 6 (A) XPS spectra of (a) $\mathrm{Cu}-\mathrm{CeO}_{2}-\mathrm{Pt}$, (b) $\mathrm{Cu}_{0.66} \mathrm{Co}_{0.34}-\mathrm{CeO}_{2}-\mathrm{Pt}$, (c) $\mathrm{Cu}_{0.50} \mathrm{CO}_{0.50}-\mathrm{CeO}_{2}-\mathrm{Pt}$, (d) $\mathrm{Cu}_{0.34} \mathrm{Co}_{0.66}-\mathrm{CeO}_{2}-\mathrm{Pt}$, (e) $\mathrm{Co}-\mathrm{CeO}_{2}-$ $\mathrm{Pt}$, (f) $\mathrm{CeO}_{2}-\mathrm{Pt}$. (B) XPS spectra of (a) $\mathrm{Cu}-\mathrm{CeO}_{2}-\mathrm{Pt}$; (b) $\mathrm{Cu}_{0.66} \mathrm{CO}_{0.34}-$ $\mathrm{CeO}_{2}-\mathrm{Pt}$; (c) $\mathrm{Cu}_{0.50} \mathrm{Co}_{0.50}-\mathrm{CeO}_{2}-\mathrm{Pt}$; (d) $\mathrm{Cu}_{0.34} \mathrm{CO}_{0.66}-\mathrm{CeO}_{2}-\mathrm{Pt}$; (e) $\mathrm{Co}-\mathrm{CeO}_{2}-\mathrm{Pt}$

respectively. ${ }^{46}$ Unfortunately, due to the low doping content of $\mathrm{Co}$ and $\mathrm{Cu}$ in $\mathrm{Cu}_{x} \mathrm{Co}_{1-x}-\mathrm{CeO}_{2}-\mathrm{Pt}$, no $\mathrm{Co}$ and $\mathrm{Cu}$ signals can be detected in all the samples. However, in combination with the HAADF-STEM characterization and ICP results, the successful formation of $\mathrm{Cu}_{x} \mathrm{Co}_{1-x}-\mathrm{CeO}_{2}-\mathrm{Pt}$ hybrids can be confirmed.

In the following, the reduction of 4-NP to 4-AP by $\mathrm{NH}_{3} \mathrm{BH}_{3}$ was selected to evaluate the catalytic performance of the asobtained $\mathrm{Cu}_{x} \mathrm{Co}_{1-x}-\mathrm{CeO}_{2}-\mathrm{Pt}$ and $\mathrm{CeO}_{2}-\mathrm{Pt}$ samples. As is known, 4-NP exhibits a strong characteristic absorption peak at $317 \mathrm{~nm}$ while at $\mathrm{pH}<7$, but it will be ionized as the alkalinity of the solution increases, resulting in a spectral shift to $400 \mathrm{~nm} \cdot{ }^{35} \mathrm{In}$ our case, the absorption peak of 4-NP remained at $317 \mathrm{~nm}$ despite adding $\mathrm{NH}_{3} \mathrm{BH}_{3}$ solution, indicating that the $\mathrm{NH}_{3} \mathrm{BH}_{3}$ molecules were stable enough in water in the absence of the catalysts. ${ }^{34}$ However, after addition of the $\mathrm{Cu}_{x} \mathrm{Co}_{1-x}-\mathrm{CeO}_{2}-\mathrm{Pt}$ hybrids, the absorption intensity at $400 \mathrm{~nm}$ gradually increased.
The color of the reaction system changed from bright yellow to colorless. Since $\mathrm{NH}_{3} \mathrm{BH}_{3}$ was in a large excess relative to 4-NP, its concentration could be considered as constant during the reaction period. Thus, the reduction rate can be evaluated by pseudo-first-order kinetics with respect to 4-NP. Fig. 7A shows $\ln \left(C / C_{0}\right)$ versus reaction time $t$, which was obtained from the relative intensity ratio of the absorbance $\left(A / A_{0}\right)$ at $400 \mathrm{~nm}$. Here, $C_{0}$ and $C$ represent the initial and instantaneous concentrations of 4-NP, respectively; and $k$ and $t$ stand for the rate constant and the reaction time in turn. As all of these plots followed firstorder reaction kinetics very well, the value $k$ can be calculated from the equation $\ln \left(C / C_{0}\right)=k t$ (Table 1 ). The catalytic activity of the six samples follows this sequence: $\mathrm{Cu}_{0.66} \mathrm{Co}_{0.34}-\mathrm{CeO}_{2}-\mathrm{Pt}>$ $\mathrm{Cu}_{0.50} \mathrm{Co}_{0.50}-\mathrm{CeO}_{2}-\mathrm{Pt}>\mathrm{Cu}-\mathrm{CeO}_{2}-\mathrm{Pt}>\mathrm{Cu}_{0.34} \mathrm{Co}_{0.66}-\mathrm{CeO}_{2}-\mathrm{Pt}>$ $\mathrm{Co}-\mathrm{CeO}_{2}-\mathrm{Pt}>\mathrm{CeO}_{2}-\mathrm{Pt}$, showing a strong dependence on the composition of $\mathrm{Cu}$ and $\mathrm{Co}$. Furthermore, the turnover frequency (TOF), defined as moles of the reactant 4-NP converted per mole of active metal in the catalyst per hour was also calculated
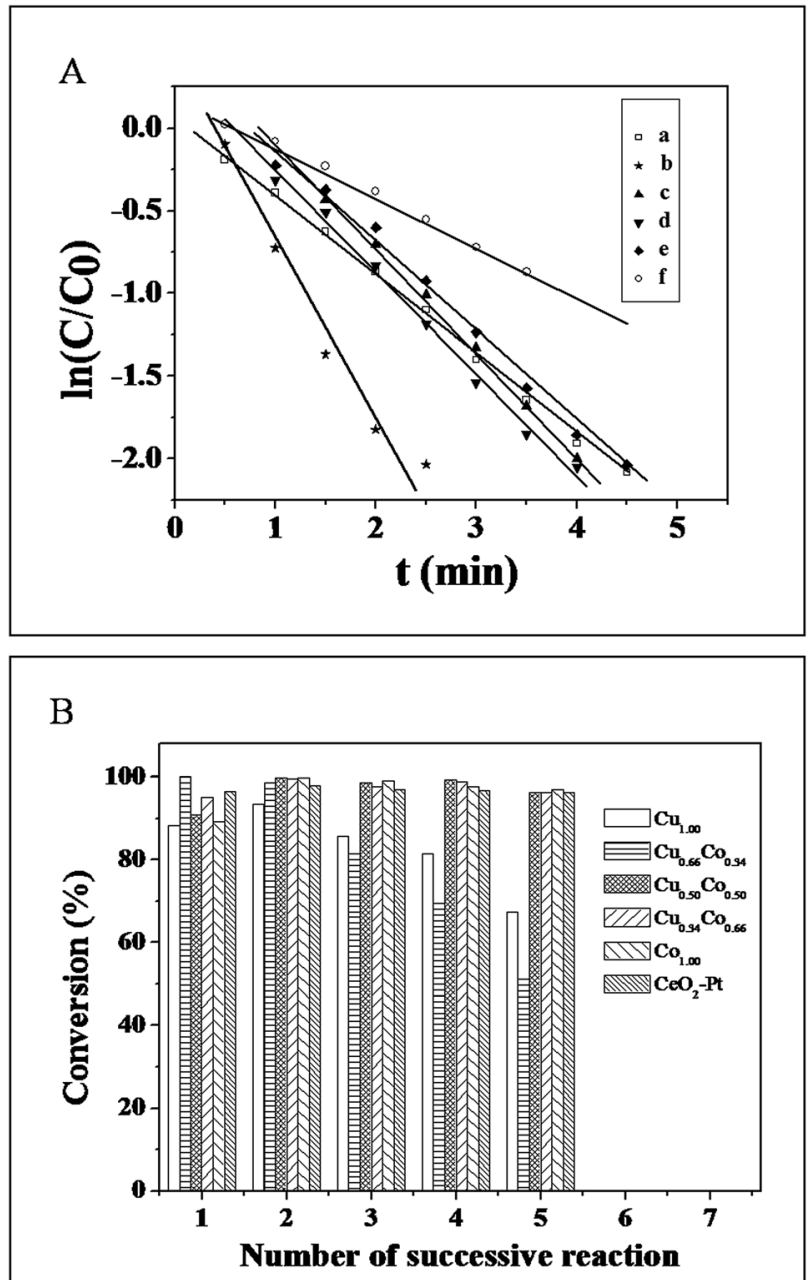

Fig. 7 (A) $\ln \left(C / C_{0}\right)$ versus $t$ for the reduction of 4-NP catalyzed by (a) $\mathrm{Cu}-\mathrm{CeO}_{2}-\mathrm{Pt}$; (b) $\mathrm{Cu}_{0.66} \mathrm{Co}_{0.34}-\mathrm{CeO}_{2}-\mathrm{Pt}$; (c) $\mathrm{Cu}_{0.50} \mathrm{Co}_{0.50}-\mathrm{CeO}_{2}-\mathrm{Pt}$; (d) $\mathrm{Cu}_{0.34} \mathrm{CO}_{0.66}-\mathrm{CeO}_{2}-\mathrm{Pt}$; (e) $\mathrm{Co}-\mathrm{CeO}_{2}-\mathrm{Pt}$; (f) $\mathrm{CeO}_{2}-\mathrm{Pt}$. (B) Conversion in successive reaction cycles of $\mathrm{Cu}_{x} \mathrm{CO}_{1-x}-\mathrm{CeO}_{2}-\mathrm{Pt}$ and $\mathrm{CeO}_{2}-\mathrm{Pt}$. 
Table 1 Comparison of the rate constant $k$, TOF and conversion for 4-NP reduction with $\mathrm{Cu}_{x} \mathrm{CO}_{1-x}-\mathrm{CeO}_{2}-\mathrm{Pt}_{\text {and }} \mathrm{CeO}_{2}-\mathrm{Pt}$ catalysts ${ }^{a}$

\begin{tabular}{|c|c|c|c|c|c|c|c|}
\hline Sample & $k\left(\mathrm{~s}^{-1}\right)$ & $M_{\mathrm{Pt}}(\mathrm{mmol})$ & $M_{4-\mathrm{NP}}(\mathrm{mmol})$ & $t(\min )$ & TOF $\left(h^{-1}\right)$ & $P(\%)$ & Ref \\
\hline $\mathrm{Cu}_{1.00}-\mathrm{CeO}_{2}-\mathrm{Pt}$ & 0.451 & $3.35 \times 10^{-6}$ & $2.00 \times 10^{-4}$ & 3.83 & 935 & 80 & This work \\
\hline $\mathrm{Cu}_{0.66} \mathrm{Co}_{0.34}-\mathrm{CeO}_{2}-\mathrm{Pt}$ & 0.995 & $7.24 \times 10^{-6}$ & $2.00 \times 10^{-4}$ & 1.88 & 882 & 51.2 & This work \\
\hline $\mathrm{Cu}_{0.34} \mathrm{Co}_{0.66}-\mathrm{CeO}_{2}-\mathrm{Pt}$ & 0.614 & $8.24 \times 10^{-6}$ & $2.00 \times 10^{-4}$ & 3.17 & 459 & 99.2 & This work \\
\hline $\mathrm{Co}_{1.00}-\mathrm{CeO}_{2}-\mathrm{Pt}$ & 0.555 & $2.05 \times 10^{-5}$ & $2.00 \times 10^{-4}$ & 3.66 & 160 & 97.8 & This work \\
\hline $\mathrm{CeO}_{2}-\mathrm{Pt}$ & 0.285 & $2.09 \times 10^{-5}$ & $2.00 \times 10^{-4}$ & 6.15 & 93 & 89.9 & This work \\
\hline
\end{tabular}

${ }^{a} M_{\mathrm{Pt}}$ : mole of noble metals; $M_{4-\mathrm{NP}}$ : mole of 4-NP; $t$ : conversion time; $P$ : conversion percentage.

(Table 1). Though the most stable sample of $\mathrm{Cu}_{0.50} \mathrm{Co}_{0.50}-\mathrm{CeO}_{2}{ }^{-}$ Pt shows a moderate catalytic activity compared to others for catalytic 4-NP conversion, its TOF of $480 \mathrm{~h}^{-1}$ is still at least five times higher than our previously reported $\mathrm{Pt} @ \mathrm{CeO}_{2}$ catalysts. $^{34}$

Good reproducibility and stability are also important for the evaluation of catalysts. In order to avoid the loss of the $\mathrm{Cu}_{x^{-}}$ $\mathrm{Co}_{1-x}-\mathrm{CeO}_{2}-\mathrm{Pt}$ catalysts caused by the separation process, cycling tests have been conducted in situ. Fig. 7B shows the conversion in successive reaction cycles of the $\mathrm{Cu}_{x} \mathrm{Co}_{1-x}-\mathrm{CeO}_{2}-$ $\mathrm{Pt}$ catalysts, and the conversions of 4-NP for the fifth cycle are listed in Table 1. It is found that the stability of the samples varied with the compositions of different doping ions, and that the Co rich samples show better stability among these catalysts.

Besides, catalytic CO oxidation was employed to evaluate these catalysts. In the catalytic process, the gas mixture of $\mathrm{CO}$ and $\mathrm{O}_{2}$ was introduced into the inner space of a stainless steel reaction tube filled with $\mathrm{Cu}_{x} \mathrm{Co}_{1-x}-\mathrm{CeO}_{2}-\mathrm{Pt}$ catalysts. $T_{100}$, the temperature for $100 \% \mathrm{CO}$ oxidation, is used to compare the catalytic activity of these samples. Despite of the minor difference in the doped components, these samples show quite different catalytic performance. Fig. 8 presents their CO conversion curves, and the $T_{100}$ values follow a sequence of: $\mathrm{Cu}_{0.50} \mathrm{Co}_{0.50}-\mathrm{CeO}_{2}-\mathrm{Pt}\left(90^{\circ} \mathrm{C}\right)<\mathrm{Cu}_{0.66} \mathrm{Co}_{0.34}-\mathrm{CeO}_{2}-\mathrm{Pt}\left(120^{\circ} \mathrm{C}\right)<$ $\mathrm{Co}-\mathrm{CeO}_{2}-\mathrm{Pt}\left(125^{\circ} \mathrm{C}\right)<\mathrm{CeO}_{2}-\mathrm{Pt}\left(135^{\circ} \mathrm{C}\right)<\mathrm{Cu}-\mathrm{CeO}_{2}-\mathrm{Pt}\left(140^{\circ} \mathrm{C}\right)<$ $\mathrm{Cu}_{0.34} \mathrm{Co}_{0.66}-\mathrm{CeO}_{2}-\mathrm{Pt}\left(155^{\circ} \mathrm{C}\right)$. It can be seen that the catalytic

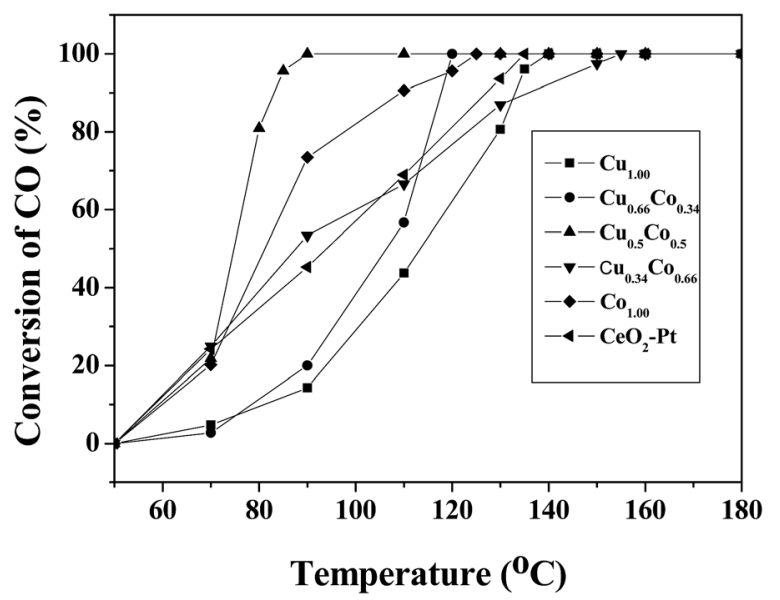

Fig. $8 \mathrm{CO}$ conversion curves of $\mathrm{Cu}_{x} \mathrm{CO}_{1-x}-\mathrm{CeO}_{2}-\mathrm{Pt}$ and $\mathrm{CeO}_{2}-\mathrm{Pt}$. performance of our samples improves with the increase in the doping amount of Co until the ratio of $\mathrm{Cu}^{2+} / \mathrm{Co}^{2+}=0.5 / 0.5$ is reached, and then this deteriorates quickly upon the doping of more $\mathrm{Co}^{2+}$ ions. This result indicates that $\mathrm{Cu}^{2+}$ and $\mathrm{Co}^{2+}$ ions can replace the tetravalent $\mathrm{Ce}^{4+}$ in the $\mathrm{CeO}_{2}$ fluorite lattice to produce more oxygen vacancies, but an appropriate doping ratio of $\mathrm{Cu}^{2+} / \mathrm{Co}^{2+}$ ions is needed in order to realize optimal catalytic performance in our case.

\section{Conclusions}

We have successfully prepared a series of $\mathrm{Cu}_{x} \mathrm{Co}_{1-x}-\mathrm{CeO}_{2}-\mathrm{Pt}$ hybrid nanospheres. Based on detailed characterization including SEM, TEM, XPS, ICP and XRD, it is found that (I) in the nucleation process, the introduction of $\mathrm{Cu}^{2+}$ accelerated the nucleation rate compared with $\mathrm{CeO}_{2}$, leading to the formation of the smaller sized $\mathrm{CeO}_{2}$. (II) The $\mathrm{Cu}^{2+}$ doping concentration can affect the amount of Pt nanoparticles deposited to a greater extent than $\mathrm{Co}^{2+}$. With the increase in $\mathrm{Cu}^{2+}$ doping concentration, the amount of $\mathrm{Pt}$ nanoparticles on the $\mathrm{Cu}_{x} \mathrm{Co}_{1-x}-\mathrm{CeO}_{2}$ nanospheres decreases. However, the related effect of $\mathrm{Cu}^{2+}$ ions was quite small. (III) The high purity of all products indicates the formation of homogeneous $\mathrm{Ce}-\mathrm{Cu}-\mathrm{Co}-\mathrm{O}, \mathrm{Ce}-\mathrm{Cu}-\mathrm{O}$ or $\mathrm{Ce}-$ Co-O solid solutions.

Based on the catalytic tests, it is also found that the doping amount of $\mathrm{Cu}^{2+}$ greatly influences the catalytic performance of the $\mathrm{Cu}_{x} \mathrm{Co}_{1-x}-\mathrm{CeO}_{2}$ nanospheres. Though the most stable sample of $\mathrm{Cu}_{0.50} \mathrm{Co}_{0.50}-\mathrm{CeO}_{2}-\mathrm{Pt}$ shows a moderate catalytic activity compared to others for catalytic 4-NP conversion, its TOF of $480 \mathrm{~h}^{-1}$ is still much higher than our previously reported $\mathrm{Pt} @ \mathrm{CeO}_{2}$ catalysts. Moreover, among the $\mathrm{Cu}_{x} \mathrm{Co}_{1-x}-\mathrm{CeO}_{2}-\mathrm{Pt}$ samples, the $\mathrm{Cu}_{0.50} \mathrm{Co}_{0.50}-\mathrm{CeO}_{2}-\mathrm{Pt}$ nanospheres exhibited the best catalytic activity, attaining $100 \% \mathrm{CO}$ conversion at $90{ }^{\circ} \mathrm{C}$, which is also higher than previously reported Pt catalysts. It can be anticipated that this kind of double doped nanocatalysts will have great potential for application.

\section{Acknowledgements}

This work was financially supported by the fundamental research funds for the central universities, and the National Natural Science Foundation of China (Grant No. 51272249, 
51372007 and 21301014). The work is also supported by the China Postdoctoral Science Foundation funded project.

\section{Notes and references}

1 S. Sen, T. Edwards, S. K. Kim and S. Kim, Chem. Mater., 2014, 26, 1918-1924.

2 M. Zeng, Y. Z. Li, M. Y. Mao, J. L. Bai, L. Ren and X. J. Zhao, ACS Catal., 2015, 5, 3278-3286.

3 D. Jiang, W. Z. Wang, L. Zhang, Y. L. Zheng and Z. Wang, ACS Catal., 2015, 5, 4851-4858.

4 W. Y. Lei, T. T. Zhang, L. Gu, P. Liu, J. A. Rodriguez, G. Liu and M. H. Liu, ACS Catal., 2015, 5, 4385-4393.

5 Y. X. Liu, X. C. Sun, B. K. Li and Y. Lei, J. Mater. Chem. A, 2014, 2, 11651-11659.

6 J. Qi, J. Chen, G. D. Li, S. X. Li, Y. Gao and Z. Y. Tang, Energy Environ. Sci., 2012, 5, 8937-8941.

7 J. M. Zhen, X. Wang, D. P. Liu, S. Y. Song, Z. Wang, Y. H. Wang, J. Q. Li, F. Wang and H. J. Zhang, Chem.-Eur. J., 2014, 20, 1-6.

8 F. Wang, X. Wang, D. P. Liu, J. M. Zhen, J. Q. Li, Y. H. Wang and H. J. Zhang, ACS Appl. Mater. Interfaces, 2014, 6, 2221622223.

9 X. Wang, D. P. Liu, J. Q. Li, J. M Zhen and H. J. Zhang, NPG Asia Mater., DOI: 10.1038/am.2014.128.

10 J. K. Edwards, J. Pritchard, L. Lu, M. Piccinini, G. Shaw, A. F. Carley, D. J. Morgan, C. J. Kiely and G. J. Hutchings, Angew. Chem., Int. Ed., 2014, 53, 2381-2384.

11 L. L. Wang, H. Huang, S. H. Xiao, D. P. Cai, Y. Liu, B. Liu, D. D. Wang, C. X. Wang, H. Li, Y. R. Wang, Q. H. Li and T. H. Wang, ACS. Appl. Mater. Interfaces, 2014, 6, 1413114140.

12 P. F. Xu, R. B. Yu, H. Ren, L. B. Zong, J. Chen and X. R. Xing, Chem. Sci., 2014, 5, 4221-4226.

13 K. Zhao, J. Qi, S. L. Zhao, H. J. Tang, H. J. Yin, L. B. Zong, L. Chang, Y. Gao, R. B. Yu and Z. Y. Tang, Chin. J. Catal., 2015, 36, 261-267.

14 K. Anupriya, E. Vivek and B. Subramanian, J. Alloys Compd., 2014, 590, 406-410.

15 P. Li, Y. Zhou, Z. Y. Zhao, Q. F. Xu, X. Y. Wang, M. Xiao and Z. G. Zou, J. Am. Chem. Soc., 2015, 137, 9547-9550.

16 K. Zhao, J. Qi, H. J. Yin, Z. M. Wang, S. L. Zhao, X. Ma, J. W. Wan, L. Chang, Y. Gao, R. B. Yu and Z. Y. Tang, J. Mater. Chem. A, 2015, 3, 20465-20470.

17 J. Qi, K. Zhao, G. D. Li, Y. Gao, H. J. Zhao, R. B. Yu and Z. Y. Tang, Nanoscale, 2014, 6, 4072-4077.

18 E. Aneggi, V. Rico-Perez, C. D. Leitenburg, S. Maschio, L. Soler, J. Llorca and A. Trovarelli, Angew. Chem., Int. Ed., 2015, 54, 1-5.

19 S. Snana, V. Esposito, J. W. Andreasen, J. Hjelm, W. Zhang, T. Kasama, S. B. Simonsen, M. Christensen, S. Linderoth and N. Pryds, Nat. Mater., 2015, 14, 500-504.

20 S. P. S. Badwal, D. Fini, F. T. Ciacchi, C. Munnings, J. A. Kimptonb and J. Drennan, J. Mater. Chem. A, 2013, 1, 10768-10782.
21 J. A. Rodriguez, S. Ma, P. Liu, J. Hrbek, J. Evans and M. Pérez, Science, 2007, 318, 1757-1759.

22 D. Jiang, W. Z. Wang, E. Gao, S. M. Sun and L. Zhang, Chem. Commun., 2014, 50, 2005-2007.

23 X. Liang, X. Wang, Y. Zhuang, B. Xu, S. Kuang and Y. D. Li, J. Am. Chem. Soc., 2008, 130, 2736-2737.

24 M. Mogensen, N. M. Sammes and G. A. Tompsett, Solid State Ionics, 2000, 129, 63-94.

25 D. Zhang, X. Du, L. Shi and R. Gao, Dalton Trans., 2012, 41, 14455-14475.

26 G. K. Reddy, G. Thrimurthulu and B. M. Reddy, Catal. Surv. Asia, 2009, 13, 237-255.

27 D. N. Durgasri, T. Vinodkumar, P. Sudarsanam and B. M. Reddy, Catal. Lett., 2014, 144, 971-979.

28 Y. X. Zhao, Z. W. Nie, M. M. Shi, C. H. Zeng, Y. Li, L. Wang and S. L. Zhong, Inorg. Chem. Front., 2015, 2, 567-575.

29 B. W. Lu, Y. W. Ju, T. Abe and K. Kawamoto, Inorg. Chem. Front., 2015, 2, 741-748.

30 A. Trovarelli, Comments Inorg. Chem., 1999, 20, 263-284.

31 Y. Tang, H. Zhang, L. Cui, C. Ouyang, S. Shi, W. Tang, H. Li, J. S. Lee and L. Chen, Phys. Rev. B: Condens. Matter Mater. Phys., 2010, 82, 125104-125112.

32 J. M. Zhen, D. P. Liu, X. Wang, J. Q. Li, F. Wang, Y. H. Wang and H. J. Zhang, Dalton Trans., 2015, 44, 2425-2430.

33 X. Wang, D. P. Liu, S. Y. Song and H. J. Zhang, J. Am. Chem. Soc., 2013, 135, 15864-15872.

34 Y. R. Zheng, M. R. Gao, H. H. Li, Q. Gao, M. N. Arshad, H. A. Albar, T. R. Sobahi and S. H. Yu, Science China Materials, 2015, 58, 179-185.

35 C. G. Hu, Q. Han, F. Zhao, Z. Y. Yuan, N. Chen and L. T. Qu, Science China Materials, 2015, 58, 21-27.

36 X. Wang, D. P. Liu, J. Q. Li, J. M. Zhen, F. Wang and H. J. Zhang, Chem. Sci., 2015, 6, 2877-2884.

37 D. P. Liu, W. Li, X. L. Feng and Y. Zhang, Chem. Sci., 2015, 6, 7015-7019.

38 T. Yu, J. Zeng, B. Lim and Y. N. Xia, Adv. Mater., 2010, 22, 5188-5192.

39 H. P. Zhou, H. S. Wu, J. Shen, A. X. Yin, L. D. Sun and C. H. Yan, J. Am. Chem. Soc., 2010, 132, 4998-4999.

40 K. Yoon, K. Yang, P. Lu, D. Wan, H. Peng, K. Masias, P. Fanson, C. Campbell and Y. N. Xia, Angew. Chem., Int. Ed., 2012, 51, 9543-9546.

41 Y. Y. Chu, Z. B. Wang, Z. Z. Jiang, D. M. Gu and G. P. Yin, Adv. Mater., 2011, 23, 3100-3104.

42 N. M. Schweitzer, J. A. Schaidle, O. K. Ezekoye, X. Q. Pan, S. Linic and L. T. Thompson, J. Am. Chem. Soc., 2011, 133, 2378-2381.

43 G. Postole, B. Chowdhury, B. Karmakar, K. Pinki, J. Banerji and A. Auroux, J. Catal., 2010, 269, 110-121.

44 W. Liu, X. F. Liu, L. J. Feng, J. X. Guo, A. R. Xie, S. P. Wang, J. C. Zhang and Y. Z. Yang, Nanoscale, 2014, 6, 10693-10700.

45 S. M. El-Sheikh, A. A. Ismail and J. F. Al-Sharab, New J. Chem., 2013, 37, 2399-2407.

46 M. Huang, Y. X. Zhang, F. Li, Z. C. Wang, Alamusi, N. Hu, Z. Y. Wen and Q. Liu, Sci. Rep., DOI: 10.1038/srep04518. 